\title{
Holding the Reigns to Demonstrate the Key Features of a Teacher Learning Community in a South African School
}

\author{
Prof Steyn GM \\ Department of Educational Leadership and Management, University of South Africa, \\ P O Box 392, Pretoria 0003, South Africa. \\ Steyngm1@unisa.ac.za
}

Doi:10.5901/mjss.2014.v5n23p1331

\begin{abstract}
Recent models of professional development of teachers focus on schools as teacher learning communities. This study is an attempt to investigate the vision of a principal and the way in which his actions brought about a teacher learning community in his school. A qualitative research design was gauged as most appropriate to illustrate the experiences of a school principal in creating and developing a collaborative learning environment for teachers in a South African primary school. Data were analysed using the six key features of a teacher learning community: leadership; focus and purpose; collaboration; relationships; inquiry; and support and building capacity. Although this study provides a basis for developing a teacher learning community, it requires contextualisation to meet a school's specific needs and challenges.
\end{abstract}

Keywords: teacher collaboration; leadership; teacher learning community; principal; professional development; case study

\section{Introduction}

For a number of years the continuing professional development (CPD) of teachers has been an area of scientific dialogue, specifically to bring about significant changes in teachers' practice and enhanced learner performance. The more recent models of CPD focus particularly on collaborative learning for teachers (Brouwer 2011; Darling-Hammond, Wei, Andree, Richardson \& Orphanos 2009; Fulton \& Britton 2011; Nehring \& Fitzsimons 2011). Studies indicate that productive collaborative relationships among teachers have the promise to constructively influence learners' academic performance and to solve problems in teaching practice (Darling-Hammond et al. 2009; Maistry 2008; Sigurðardóttir 2010).

For teacher learning to be successful, it is not only required that teachers work together, but it is also recognised that school leaders play an important role in this process (Louis, Dretzke \& Walhstrom 2010). Principals exert a greater impact on teachers' practice when they work cooperatively with teachers on aspects that influence their classroom practice, including decisions about who teachers should collaborate with, what their responsibilities are and what support they require in developing new professional skills (Louis et al. 2010; Printy 2010). Very few studies have focused on the measures principals have taken to initiate, sustain and support collaborative learning among staff members in schools (Gaspar 2010). This study, which is a follow-up on previous studies in the school (Steyn 2013a; 2013b), endeavoured to contribute to the current body of knowledge by explaining how the principal addressed the key features of teacher learning community in the school.

Previous studies at the school revealed strong principal leadership behaviours; a sense of shared responsibility for learners' and teachers' learning; and a strong commitment to teacher collaboration (Steyn 2013a; 2013b). The school was also a recipient of the Inviting School Award from the International Alliance for Invitational Education during the predecessor's time in office. In essence Invitational Education is a theoretical framework and practical strategies that aims to create and sustain people to work together to create effective schools (Newsletter of the International Alliance of Invitational Education 2012). The following research problem emerged in this study: How did the principal manage the teacher collaboration at his school and how did the principal's actions and behaviours demonstrate the key features of a teacher learning community?

\section{Conceptual Framework}

Various studies show that teacher collaboration within teacher learning communities have great potential to promote 
teacher and school learning by offering opportunities to improve teachers' practice (Conley, Fauske \& Pounder 2004; James, Dunning, Connolly \& Elliott 2007; Maistry 2008; Sigurðardóttir 2010). However, a review on the literature regarding teacher collaboration shows a lack on conceptual clarity regarding the concept "teacher collaboration" (Brouwer 2011). For the sake of this study teacher collaboration is viewed as a team of teachers who work collectively and purposefully to create, improve and sustain their own learning and, ultimately, that or their learners (Greer 2012).

Teacher professional learning models that enhance teacher collaboration focus on the creation of structural conditions to remove teacher isolation and sustain and encourage teachers' learning to accomplish shared learning goals collaboratively (Blacklock 2009; Stoll et al. 2006). These structural conditions are longer in duration and, inter alia, encourage shared leadership, a shared vision and shared professional practice and is focused on student learning (Williams 2010). Chappuis, Chappuis and Stiggins (2009:60) state that through collaboration teachers are introduced to new ideas and provided with opportunities to learn together: "Collaborative learning teams can transform the nature of adult interaction and learning in the schools by engaging teachers in the same process of continual learning and improvement that we ask our students to strive for in their work."

Although studies shows the complex nature of teachers' professional learning (Sigurðardóttir 2010; Printy 2010) the model of professional learning presented by Opfer, Pedder and Lavicza (2011) suggests that there are shared learning beliefs and practices in schools which constitute a school's organisational orientation to teacher learning. In essence it means that professional learning can only be understood when there is an understanding of the role that the school plays in teachers' learning (Opfer et al. 2011). It is, in particular, principals who play a major role in providing a conducive environment in which teacher collaboration can take place (Louis et al. 2010; Printy 2010). In this regard, DuFour and Marzano (2009) state that principals are far more likely to improve students' performance when they support teachers' learning through collaborative teams in the schools. This implies that principals need to create and support appropriate structures in which teachers can engage in professional dialogue to improve both teacher and student learning (DuFour \& Marzano 2009; Jakicic 2009). Katz and Earl 2010 (29-32) identify six key features of teacher learning communities, which are also supported by the insights of other studies.

\subsection{The role of leadership}

The school culture that principals promote, contributes to the way in which staff members interact professionally. By providing encouragement, support and capacity building, principals show the necessary leadership to create a context for teacher collaboration in the school. It promotes a culture of collaboration, collegiality, support and trust, which are all firmly embedded in democratic beliefs and values, with a view to empower staff and improve their teaching practice (Katz \& Earl 2010; Raihani 2008). As such, principals' leadership behaviour and actions may have an influence on professional relationships, professional development and school development (Hallinger \& Heck 2010; Kelly \& Saunders 2010).

\subsection{Focus and purpose}

A learning focus in teacher collaboration is based on evidence that it can have a significant impact on both teachers' classroom practices and student performance (Katz \& Earl, Jaafar, Elgie, Foster, Halbert \& Kaser 2008). According to Fulton and Britton (2010) and Nehring and Fitzsimons (2011) the first key factor for effective teacher collaboration is a shared vision and shared responsibility for student performance. It is, however, important that the type of teacher learning be adapted for a particular school, taking into consideration its context, needs and history (Katz \& Earl 2010).

\subsection{Relationships}

Through collegial relationships teachers create a common language and they create the necessary channels for communication, which are based on trust (Hargreaves 2007). Understanding the dynamics of relationships in a team is important, since it shapes what is learnt in the team (James et al. 2007). In teams the members develop a common sense of professional identity, develop certain relationships and ways of interacting and also develop a body of common practices, knowledge and approaches (Li, Grimshaw, Nielsen, Judd, Coyte \& Graham 2009). Collaboration, however, includes more than mere relationships, since it refers to intensive interaction in which teachers are engaged so that their practices and beliefs can be investigated and debated (Katz \& Earl 2010). 


\subsection{Teacher collaboration}

Collaboration is viewed as the professional activity in which teachers, in their teams, share experiences, skills and knowledge that can enhance their instructional practice and ultimately improve student performance (Goddard, Goddard \& Tschannen-Moran 2008; James et al. 2007; Williams 2010). Once teachers are involved in a "dynamic process of interpretation and evaluation of practice" they promote their own practice and that of the profession (Katz \& Earl 2010).

\subsection{Inquiry}

In collaborative inquiry teachers have the opportunity to search for and take various sources of knowledge into account to review their classroom practices through various lenses for the sake of improved practice. This "way of thinking" is a dynamic system which involves the organising of ideas and information seeking in order to gain a closer understanding of certain educational phenomena (Katz \& Earl 2010). Moreover, on-going collegial dialogue, where teachers share their beliefs, classroom practices and experiences and design lessons together, has been identified as a key feature of successful schools.

\subsection{Providing support and building capacity}

Conducive conditions that support both individual and collective learning are required for teacher collaboration. This implies that professional learning in schools needs to be planned and organised in such a way that teachers are regularly engaged in professional dialogue (Darling-Hammond, et al 2009; Nehring \& Fitzsimons 2011). This can be done by organising teachers into horizontal teams, based on their grade level, and vertical teams, based on content learning areas (Darling-Hammond et al. 2009). As teams they commit themselves to a cycle of continuous student improvement in order to identify and address learners' needs.

\section{Research Design}

For this study I focused on the role the principal played in teacher collaboration in a primary school. I attempted to give the principal the opportunity to share his experiences of initiating and leading teacher collaboration in his school. A qualitative research design, in particular a descriptive, single case study, was used in a bounded system to have an indepth understanding of the phenomenon (Gaspar 2010; Greer 2012): that is, how the principal held the reigns in teacher collaboration in the inviting school. This study was located in the constructionistic/interpretive paradigm, since it investigated the way in which the principal interpreted and made sense of his leadership role while developing and establishing teacher collaboration in the school (Gribich 2013). The data for this study were collected through individual interviews that I conducted with the principal in 2012 and 2013 at prearranged times in his office. The questions posed predominantly focused on the following aspects: the principal's leadership role in teacher collaboration, the way in which the teams functioned, the requirements of effective teacher collaboration and the impact of teacher collaboration.

The narrative data collected were recorded, transcribed and analysed. The data analysis was done by means of selective coding (Creswell 2007) where codes were systematically and deductively identified with respect to the phenomenon, that is, teacher collaboration. Although not intentional, when reviewing the literature, it led to "a priori coding" by default (Nieuwenhuis 2010a:60). Since people's life world depends on human knowledge it means that a priori knowledge influences the interpretation of phenomena (Nieuwenhuis 2010a). The key features of effective teacher learning communities identified by Katz and Earl (2010) were used in analysing the data. These a priori categories (Nieuwenhuis 2010b) used in coding, were to "test" the existing theory of teacher collaboration in the school. The validation strategies included member checking through the use of e-mails to the principal before and after the data were analysed, triangulation by employing the relevant literature and theories to corroborate evidence, prolonged engagement with the principal and rich and thick descriptions of the principal's views served (Creswell 2007).

Ethical clearance for the study was approved by the Gauteng Department of Education and the University of South Africa. The principal also willingly gave his consent to continue to participate in the study.

\section{Findings}

The key focus of this study was to understand the principal's leadership role in creating the professional teacher community within his school. The location was an Afrikaans, urban, primary school situated in Gauteng, in a middle class 
community with "many rich and many poor families". The school had approximately 1750 students at the time of the study. The principal in this study took office at the beginning of 2010. Based on the school's vision and mission, which focused on academic excellence, the school strived to attain excellence through quality professional development of teachers. This academic focus became "very strong". He viewed himself as a "control freak" in his efforts to attain his goal of providing "a good service". It was also a great challenge for the principal to change teachers' attitude about academic work and their professional development.

After observing the isolation in which teachers worked, the principal intentionally created a teacher collaboration structure during his second year in office. To ensure that this goal was attained, the principal stated that he had to work very hard to convince all the teachers to support this initiative and to share his vision of teacher collaboration.

The next six sections, which are based on the six key features of teacher learning communities by Katz and Earl (2010), show how a collaborative learning environment for teachers were designed and managed in the school.

\title{
4.1 The role of leadership: "It was my job and still is to make sure that there is cohesion."
}

The principal acknowledged the "very important role" he played in the school and considered his leadership style to be "task-oriented", but "a mixture, something between extremely democratic and sometimes autocratic". As regards his leadership style he explained:

\begin{abstract}
I am someone who believes that if you take on a task, you do it well. I think that if we want to call our school a school of excellence we have to ensure that everything is in place ... I know that I wasn't always the most popular guy, but I believe that this is something that had to be done... I am prepared to wear a pair of boxing gloves ... and I fully accept that we are not here to be best mates, we are here to work and we do it well. I try to be a "nice" guy and a "friendly" guy, but it is a challenge.
\end{abstract}

Although he liked "measurable results", he believed that he was also "accessible" and that he cared about the people he worked with. He preferred to consult with staff members, to involve people when decisions affect them and to have consensus on issues. However, he also had to make certain without consensus, since he was ultimately accountable for the outcomes.

The principal indicated that the school previously "had little islands of excellence" with no cohesion among staff members. As driving force behind teacher collaboration he had to create appropriate structures in the school or to merely streamline those that existed. He ensured that all teachers were "on the same page" by understanding the necessity of collaborative structures and seeing "the big picture". He elaborated:

It was my job and still is to make sure that there is cohesion and there can only be cohesion if everyone understands where we are going and why we are going there. So I have to tell them that, I have to teach them that and I have to monitor them, that is my role.

The principal was very humble in establishing teacher collaboration in the school and did not attribute its success to himself. However, instituting collaboration was not without its challenges. At the end of his third year in office and with a more informed understanding of the functions of the senior management team of the school, he decided to restructure the management team of the school. Although he discussed his initial decision with the people who would be affected by it, this decision was essentially his "own" decision and was received with "a little bit of apprehension and may be a little resentment". One senior staff member took it "personally" when certain responsibilities were delegated to other staff members to relieve her heavy workload. Although his motive was not to bore them with details, the principal realised that he should have given staff more details about his decisions for the sake of clarity. The principal learnt a lot from this incident and also assisted him to reconsider his management style.

Leadership is critical for teacher collaboration, as the principal in this study demonstrated. The principal in the study accepted the responsibility for setting up teacher collaboration at the school (Hallinger \& Heck 2010; Kelly \& Saunders 2010). It necessitated the development of appropriate leadership behaviours to ensure that there was a shared vision among staff members which would foster a commitment to the process (Andrews \& Lewis 2002; Williams 2010:22). Williams (2010) shows that critical leadership attributes that promote teacher collaboration include attributes such as persistence and determination. Without persistence to ensure progress, the vision of collaboration cannot be achieved; while determination is necessary to overcome the challenges and hardships they have to endure while they pursue their goal (Williams 2010).

In line with the findings of Moller (2006), the principal's actions revealed the following: (1) the principal was willing to listen to teachers and considered their complaints and concerns as important issues that had to be addressed; (2) he 
assumed the responsibility of gaining information to understand what was happening in the school; and (3) he realised that monitoring was essential to ensure that measureable results were achieved (Moller 2006). It is particularly through encouragement that principals provided the necessary leadership in the process of establishing teacher collaboration in the school (Katz \& Earl 2010).

\subsection{Focus and purpose}

In the principal's first year in office the school's vision and mission were reviewed. The governing body, the senior management team and several other role players made major changes to it: they were completely innovative with their thinking. The principal indicated that the academic focus in the school shifted 180 degrees: "Academic work has always been important to me ... this is our core business, and that is why we are here."

With the principal's focus on teacher collaboration, it implied that the whole academic policy and structure in the school also had to change. The principal inter alia introduced weekly scheduled tests and a mid-year examination, instead of only tests during the year. With a limited budget the principal could only reduce the number of learners in the Maths class in Grade 7 in his first year as principal. Since then the system had been extended to include Grades 5 and 6. This had a "tremendous" positive impact on the performance of learners and the principal was "extremely pleased" with its success.

As regards the focus and purpose of teacher collaboration, the principal stated that he set specific objectives, focused on these objectives and tried to achieve them together with his teachers. Since his goal was to achieve "excellence" and not merely good service, he had to know exactly how each teacher worked in the classroom. Their continuous professional development to improve their practice was of major importance him, but not all teachers initially shared the same view. He perceived this as "a crisis" and he had to work very hard to change teachers' attitude regarding their professional development. Teachers had to be convinced of the advantages of managing their own professional development, which occurred and resulted in "a positive vibe" in the school. Teachers should never stagnate and feel that they had "arrived". He therefore encouraged "innovative thinking" and continuously challenged teachers to continue "to strive to higher and better... to move to the so-called 'next level'", which he considered to be crucial for effective teaching. The aim should be to become a better teacher and ultimately to become a better human being.

Although particularised for the school setting, the findings are supported by the literature. This principal focused on learning in his school to strengthen teachers' professional practice instead of focusing on what is taught or how it is taught (DuFour \& Marzano 2009). This implied that he created an academic vision that focused on student performance (Blacklock 2009; Stoll et al. 2006), and by doing so created a school culture that contributed to the way in which staff members interacted professionally (Katz \& Earl 2010; Raihani 2008).

In principals' intentional focus on learning they attempt to search for and create the necessary activities and opportunities to move beyond the current status quo in the school (Katz \& Earl 2010; Katz et al. 2008).

\subsection{Teacher collaboration: "Success in the classroom depends $100 \%$ on teacher collaboration."}

Studies show that teacher collaboration has great potential to enhance both teacher and student learning by offering opportunities to develop and improve classroom practice (Goddard et al. 2008; Maistry 2008; Sigurðardóttir 2010). In the principal's first year in office he observed that teachers worked in a "very isolated" way. The different grades functioned independently and teachers considered their particular grade as the best in the school which hampered to the overall performance in the school. Although the principal realised that change was difficult, he was of the opinion that he could not leave "things unchanged". Academic collaboration was of "paramount importance" and classroom success depended "hundred percent on teacher collaboration". He was convinced that without collaboration and continuity staff would pull in different directions and the school would fail the learners.

According to the principal, getting the cooperation of staff as "a huge step". Many teachers cried "crocodile tears", but the principal was adamant that these changes had to be done, but the teachers still had to be convinced for it to be successful. The majority of teachers were willing to listen, could eventually see the "bigger picture" and realised that they were "interdependent". The principal explained that it was important that teachers should know how to prepare learners for the next grade to ensure continuity. In his fourth year the principal could confidently state that the system was in place and that the transition from one grade to the next was "almost $80 \%$ less traumatic, merely because of the better communication between grades". The outcome was "just so amazing" and he was exceptionally proud of this achievement.

The principal acknowledged that the dynamics, culture and socio-economic circumstances in other schools had to 
be taken into account when introducing teacher collaboration. He therefore suggested that schools that consider to institute teacher collaboration should start to with "baby steps". A condition was that everybody in the school should be "on board" and share the same vision before the principal could ensure successful teacher collaboration.

Considering the findings, it was clear that the principal wanted to establish teacher collaboration (Williams 2010) as a matter of urgency and, in so doing, he also succeeded in removing the isolation among teachers in the school (Fulton \& Britton 2011; Printy 2010; Sigurðardóttir 2010). He articulated a clear vision and teachers could identify with the reasons for working collaboratively with colleagues (Williams 2010). As indicated in the findings teachers did not initially support collaboration. The principal therefore encouraged a collegial focus on improved student learning through continuity and communication (Williams 2010) and established collaborative opportunities to foster the development of stronger, more cooperative relationships among staff members (Blacklock 2009).

\subsection{Relationships: "It [the success] is not because of me, it is because of the others [teachers]."}

For effective teacher collaboration it is important that the principal work in close collaboration with the teachers in order to understand their beliefs, values and concerns regarding teaching (Fleming 2007). The principal in the study had a clear understanding of what teachers did in their classrooms and what they needed to effectively execute their responsibilities in the school. This provided him with the necessary information to make informed decisions. He maintained that nothing would happen if principals stayed in their offices, "drinking coffee with guests since they should be actively involved in teaching. He stated: "I teach a class as well...I wouldn't be aware of what is demanded of and what is required by teachers if I wasn't teaching."

Conducive relationships between the principal and teachers and among teachers are based on certain conditions. The principal believed that teachers should acknowledge their colleagues' abilities and expertise and be willing to work together. Moreover, "The basis of all of this is that they understand where they are supposed to be going and that they buy into that. If they have the same goal, then they will be successful."

On a number of occasions the principal mentioned the importance of trust in each other and trust in the process: "If they trust me, they will come with me ... that is because we trust each other ... When they trust you, even if they do not agree, they will go with you ... but it takes time to get there".

Regarding the relationship among staff members, the principal acknowledged his crucial role: "I am the cog in that big machine, without which the machine won't be able to run ... There should be someone who takes responsibility or accountability." Nevertheless, the principal modestly admits that the staff had made an indispensable contribution to ensure that the school achieves its goals:

To be brutally honest, no outcome has been reached because of me ... the outcomes have been reached despite me ... I will never be able to say that we have accomplished anything if I didn't have the support of the others ... It is not because of me, it is because of the others.

What amazed the principal was the type of relationship that developed among teachers as the result of their collaboration; a form of "brotherhood" among the 106 staff members. The principal did not know how this developed, but this encouraged him to work his "fingers to the bone" and he believed that teachers were also willing to do this for him.

A factor that the principal believed could inhibit teacher collaboration, was the different personalities and diverse opinions of teachers. However, the ability to manage those differences was "the art of this whole thing ... If you believe in what you are doing, you will get past yourself and over yourself and you will buy into where you go".

The findings show that the collaborative processes established by the principal fostered the development of relationships between the principal and staff members and among the staff members, respectively (Blacklock 2009). Collaboration in this school brought the principal and teachers together to form close professional relationships and it also served as the foundation from which relationships of trust had developed as they strived to achieve a common goal (Greer 2012; Hallinger \& Heck 2010; Williams 2010).

Teacher collaboration includes more than merely building relationships, since it involves intensive interaction and dialogue in which teachers are engaged so that their classroom practices and beliefs can be investigated and debated (Katz \& Earl 2010).

\subsection{Inquiry: "We need to share intellectual property with each other."}

Teacher collaboration is essentially an inquiry-based approach where staff members collectively investigate their teaching practice for the sake of improved teacher and student performance (Nehring \& Fitzsimons 2011; Williams 2010). Recalling his teaching experience, the principal stated that sharing "intellectual property" was initially difficult for staff 
members and almost "against human nature". He argued that teachers, especially Afrikaners, didn't share their intellectual property easily and were even in competition with each other. This competitiveness was "ridiculous" and should be discouraged. He believed that sharing intellectual property was necessary which was eventually "very rewarding".

With teachers' changed attitudes about sharing intellectual knowledge teachers often invited other teachers to observe their lessons in class. For the principal this was "fantastic" because it showed that teachers had confidence in their abilities and that they had the freedom to initiate such learning opportunities. To ensure effective dialogue the principal believed that teachers should share the same teaching and learning goal; "Only when they [the teachers] know why and where the destination is, they will get to the how". The dialogue, however, depended on the subject, "the bigger picture" and the envisaged "outcome".

It is evident from the findings that the principal created a non-threatening environment for teachers to engage in professional dialogue. Appropriate dialogue, which is a key activity for both individual and collective construction of meaning, is also supported by the literature (Fulton \& Britton 2010; Greer 2012; Jakicic 2009; Katz \& Earl 2010; Nehring \& Fitzsimons 2011; Pedder \& Opfer 2011). In this regard Williams (2010:151) states: "The beneficial nature of interactive dialogue expands the expertise of individuals, utilizing the pooled experiences of multiple people." Moreover, the collective inquiry of teachers assisted in strengthening contact between teachers, stimulating dialogue and helping them to build on each another's expertise (Fulton \& Britton 2010). This implies, however, that principals need to create and support the necessary structures to ensure teacher collaboration.

\subsection{Providing support and building capacity: "It is my job and my duty to identify which structures or teams have to be there."}

Pedder and Opfer (2011) argue that teacher learning occurs primarily as the outcome of the necessary support systems and the interaction of teachers working collaboratively. This was supported by the principal who stated that teacher collaboration should be in a structure, which had to be monitored and guided to ensure continuity. Although the principal considered the implementation and maintenance of continuity as "a challenge", he indicated his role in realising this: "It is my job and my duty to identify which structures or teams have to be there."

To ensure that teachers collaborated on different levels and on various occasions, he referred to the way in which collaboration was structured in the school. The principal, for example explained that the Maths Department convened once a week and the Maths teachers for each grade three times per week. The staff meetings were held on Tuesdays and Thursdays before the school day started while the school management team met on Wednesdays. Teachers also daily spoke informally to each other to ensure that they covered the same work on that particular day. The many different interactions meant that repetition often occurred.

The principal used the example of grade meetings in the Foundation Phase to explain how teachers in this phase worked together. Teachers worked in cycles, with each cycle one topic would be chosen as the theme for all the different learning areas. These teachers shared their questions and their work charts and ensured that they all did exactly the same work and had the same approach. Teachers also took turns to work out work charts for the different learning areas and by doing this they also learnt from each other.

Finding and structuring appropriate time for collaboration was "a huge obstacle" for the principal, especially with the required $271 / 2$ hours contact time per week. To comply with this requirement, without extending the school day, the school had one assembly on a Monday and a test period on a Thursday. The school scheduled meetings during the 45 minute assembly period, and others mostly after school or during breaks.

The principal also explained the role of team leaders in the functioning of teams. "There are many different very well-qualified people who are in charge of groups ... we sit together and we pull it [the structuring] together." To a large extent decisions are made within teams, since the principal did no regard it as "proper" to impose decisions.

Principals exert a great impact on teachers' practice when they provide the necessary structures and support for teacher collaboration (Louis et al. 2010; Printy 2010).

The principal in this study accepted the responsibility to create the necessary structures and to ensure that teachers had sufficient time to engage in professional dialogue (Fulton \& Britton 2011; Nehring \& Fitzsimons 2011; Williams 2010). The weekly staff meetings, as well as the grade and subject meetings, showed that the principal used cross-team dialogue to create opportunities where teaching practices and beliefs could be shared (Jakicic 2009).

Considering the processes involved in the implementation of teacher collaboration in the school, the principal succinctly explained that the school had come "a long way" for continuity to occur. He stated: "Collaboration is key in our school now and people are actually proud of sharing with other people. I love that." 


\section{Conclusion}

With the increasing pressure for more accountability in schools, it has become vital for school principals to implement appropriate professional development models. The collaborative design discussed in this study suggested that strong leadership and a shared vision for collaboration are required. The findings in the study showed that the principal undertook to create teacher collaboration in the school and to revitalise teachers' passion for professional learning. Although teachers initially felt uncomfortable about collaboration, they were eventually convinced about the advantages of working collaboratively with their peers. The principal introduced both horizontal and vertical teams to ensure professional learning, continuity and communication. By doing this, he successfully created an appropriate context in which teachers shared their teaching practices. Their professional relationships also extended to personal relationships.

The themes identified in this study provide a tentative theoretical framework to have a better understanding of teacher collaboration and have certain implications for practitioners who intend to implement teacher collaboration in their schools. The following implications can be drawn for this study:

- Teachers need to buy into the collaborative model by having a clear understanding of the purpose and value of teacher collaboration.

- Schools require policies to enhance teacher collaboration in the school. Teacher collaboration also requires an appropriate vertical and horizontal structure, including scheduled times to provide opportunities to discuss, debate and share classroom practices.

- The sustainability of a professional community within a school depends on teachers' experience of their professional growth and the improvement of learners' performance as a result of their professional learning.

- Principals need to monitor teacher collaboration to sustain its effective functioning and make the necessary adaptations, depending on the internal and external forces influencing the school.

- School contexts differ and have a unique set of teacher communities which means that schools need to approach teacher collaboration in ways that work best and are appropriate for their particular setting.

The following studies for future research are recommended: investigating the type of leadership and leadership qualities that are required for effective teacher communities; investigating the conditions that are required to promote teacher communities in schools; identifying the role of principals and teachers in maintaining a culture of teacher communities; and understanding community building in teams in previously disadvantaged schools is recommended. More empirical studies, in particular longitudinal studies, are also required to investigate the contextual factors that promote the sharing of knowledge and skills in teacher communities.

\section{References}

Andrews, D. \& Lewis, M. (2002). The experience of a professional community: teachers developing a new image of themselves and their workplace. Educational Research, Winter, 44(3),237-254.

Blacklock, P.J. (2009). The five dimensions of professional learning communities in improving exemplary Texas elementary schools: a descriptive study. Dissertation, Doctor of Education. University of North Texas, United States of America.

Brouwer ,P. (2011). Collaboration in teams. Doctoral thesis, University of Utrecht, Netherlands.

Chappuis, S., Chappuis, J. \& Stiggins, R. (2009). Supporting teacher learning teams. Educational Leadership, 66(5), 56-60.

Creswell, J.W.( 2007). Qualitative inquiry and research design. Choosing among five approaches. 2nd edition. Thousand Oaks, CA: Sage.

Darling-Hammond, L., Wei, R.C., Andree, A., Richardson, N. \& Orphanos, S. (2009). Professional learning in the learning profession: a status report on teacher development in the United States and abroad. Dallas, TX: National Staff Development Council. [Online] Available: http://www.learningforward.org/docs/pdf/nsdcstudy2009.pdf (August 13, 2013).

Dufour, R. \& Marzano, R.J. (2007). High-leverage strategies for principal leadership. Educational Leadership, 66(5), 62-68.

Fulton, K. \& Britton, T. (2010). STEM teachers in professional learning communities: a knowledge synthesis. [Online] http://www.wested. org/online_pubs/resource1097.pdf. (August13, 2013)

Fulton, K. \& Britton, T. (2011). STEM teachers in professional learning communities: from good teachers to great teaching. [Online] Available: http://www.literacyinlearningexchange.org/STEM\%20Teachers\%20in\%20Professional\%20Learning\%20Communities (August 20, 2013)

Gribich, C. (2013). Qualitative Data Analysis: An Introduction. London: Sage.

Goddard, Y.L., Goddard, R.D. \& Tschannen-Moran, M. (2008). A theoretical and empirical investigation of teacher collaboration for school improvement and student achievement in public elementary schools. Teachers College Record, 109(4),877-896.

Greer, J.A. (2012). Professional learning and collaboration. Doctoral dissertation. Virginia Polytechnic Institute and State University.

Hallinger, P. \& Heck, R.H. (2010). Collaborative leadership and school improvement: understanding the impact on school capacity and student learning. School Leadership and Management, 30(2), 95-110. 
Jakicic, C. (2009). How principals can make a difference. [Online] Available: http://wvde.state.wv.us/principalsinstitute/institute0809/docs_spring/SpringDay02_Jakicic_PLC_Handout.pdf (February 6, 2013).

Newsletter of the International Alliance of Invitational Education. (2012). Invitational Education Forum, 33(11),1-10. [Online] http://www.iaiewc2012.org.hk/pdf/FORUM\%20April\%202012.pdf ( November 19, 2013).

Katz, S. \& Earl, L. (2010). Learning about networked learning communities. School Effectiveness and School Improvement, 21(1), 2751.

Kelly, A. \& Saunders, N. (2010). New heads on the block: three case studies of transition to primary school headship. School Leadership and Management, 30(2), 127-142.

Li, L.C., Grimshaw, J.M., Nielsen, C., Judd, M., Coyte, P.C. and Graham, I.D. (2009), "Evolution of Wenger's concept of community of practice", Implementation Science, 4(11), 1-8. [Online] Available:http://www.ncbi.nlm.nih.gov/pmc/articles/PMC2654669/pdf/ 1748-5908-4-11.pdf (January 8, 2013. .

Louis, K.S., Dretzke, B. \& Walhstrom, K. (2010). How does leadership affect student achievement: results from a national US survey. School Effectiveness and School Improvement, September,21(3), 315-336.

Maistry, S.M. (2008). Towards collaboration rather than co-operation for effective teacher professional development in South Africa: insights from social practice theory. Southern African Review of Education, 14(1), 119-142.

Moller, G. (2006). Teacher leadership emerges within professional learning communities. Journal of School Leadership, 16(5), 520-533.

Nehring, J. \& Fitzsimon, G. (2011). The professional learning community as subversive activity: countering the culture of conventional schooling. Professional development in Education, 37(4), 513-535.

Nieuwenhuis, J. (2010a). Introducing qualitative research. In K. Maree (Ed.), First Steps in Research (pp. 46-68). Pretoria: Van Schaik:

Nieuwenhuis, J. 2010b. Analysing qualitative data. . In K. Maree (Ed.), First Steps in Research (pp. 99-122). Pretoria: Van Schaik.

Opfer ,V.D., Pedder, D.J. \& Lavicza, Z. (2011). The influence of school orientation to learning on teachers' professional learning change. An International Journal of Research, Policy and Practice, 22(2), 93-214

Pedder, D. \& Opfer, V.D. (2011). Are we realising the full potential of teachers' professional learning in schools in England? Policy issues and recommendations from a national study. Professional Development in Education, 37(5), 741-758.

Printy, S. (2010). Principals' influence on instructional quality: insights from US schools. School Leadership and Management, 30(2), $111-126$.

Raihani. (2008). An Indonesian model of successful school leadership. Journal of Educational Administration, 46(4), 481-496.

Sigurðardóttir, A.K. (2010). Professional learning community in relation to school effectiveness. Scandinavian Journal of Educational Research, 54(5), 395-412.

Steyn, G.M. (2013a). Principal succession: the sosialisation of a primary school principal in South Africa, Koers: Bulletin for Christian Scholarship. 78(1) [Online] Available: Art. \#426, 9 pages. http://dx.doi. org/10.4102/koers.v78i1.426] (July 23, 2013)

Steyn, T. (2013b). Professional and organisational socialisation during leadership succession of a school principal: a narrative inquiry using visual ethnography. South African Journal of Education, 33(2), 315-332.

Stoll, L., Bolam, R., Mcmahon, A., Wallace, M. \& Thomas, S. (2006). Professional learning communities: a review of the literature. Journal of Educational Change, 7, 221-258.

Williams, M.L. (2010). Teacher collaboration as professional development in a large, suburban high school. Unpublished PhD thesis. Lincoln, Omaha: University of Nebraska. 